\title{
Concelto de Ciência: Tradição Tecnológica e Contingência do Conhecimento
}

\author{
PROF. FRANCISCO LUIS GARCIA \\ Centro de Ciências Biológicas
}

A Tecnologia não surgiu da Ciência; pelo contrário, é possível que, cronologicamente, ela a tenha precedido - ao menos não temos indícios, e nem poderíamos ter, de quaisquer atividades proto-científicas, ou mesmo proto-filosoficas, anteriores à descoberta da ferramenta pelo homem. Poderíamos argu-
Mas, é provável que, após ter emergido de uma preocupação puramente pragmática, a ciência tenha se desvinculado da tecnologia quase que por inteiro, pois, senhor absolùto do mundo que habitava, pelas ferramentas que desenvolveu, o homem tenha podido atentar, com mais vagar`a tranqüilidade, ao

\section{RESUMO}

Discute-se, no presente trabalho, as origens da Ciência, sua similaridade com o conhecimento filosófico, e sua avaliação, através de uma tecnologia especifica. Considera-se também o problema da observaçâo empirica, enfatizando-se a necessidade de uma nova abordagem que deveria examinar os aspectos ignorados do fenômeno em observação.

mentar, é claro, que a razão ou o raciocínio tenha levado o homem a observar meticulosamente seu derredor e, destarte, a visualizar, antes mesmo de efetiválo, o uso e a aplicação dos objetos que estavam a seu lado, dentro de um processo de "domesticação" de suas cirscunstâncias. No entanto, existem algumas evidências, de natureza lógica e não empírica, de que a descoberta do instrumento se tenha dado por um golpe do acaso, isto é, que ela tenha sido inteiramente fortuita. E, é claro, descoberta pela primeira vez a utilidade de um obje to qualquer, o homem, podemos supô-lo, passou a buscar, com mais atenção agora, outros objetos que também poderiam lhe ser úteis. Possuidor desses instrumentos, era mister aperfeiçó-los para que melhor se adaptassem ao manejo e à finalidade proposta - a transformação do instrumento em ferramenta pela alteração de suas características originais. Dessa busca orientada, talvez tenha nascido a observação reflexiva, e da intençao de aperfeiçoá-los, a manipulação, ainda que através de tentativas por ensaio-e-erro, tuas das características básicas do método científico.

\section{ABSTRACT}

The origins of Science, its similarity with the philosophical knowledge, and its evaluation through a specific technology are discussed in the study. The problem of empiric observation, emphasizing the necessity for a new approach that should deal with the aspects which are ignored in the phenomenon in observation, is also considered.

seu derredor, livre das preocupações prementes de sobrevivência: olhar para cima e constatar a existência de incontáveis astros em permanente revolução; buscar novos horizontes e novas paisagens. Aí, talvez, o início do processo de investigação, o berço do conhecimento, as origens da Ciência e da Filosofia, ainda que, hoje, os métodos de uma e outra sejam bastante diferentes. 0 método de investigação científica se inicia e se estrutura sobre uma atividade observacional, a partir da qual reunimos alguns dados sobre um fenômeno enfocado e os interpretamos para, em seguida, con cluirmos algo sobre aquele fenômeno. Assim, a metodologia científica ê limitada, desde o princípio, pelo equipamento sensorial de que dispomos, e nada nos assegura que este nos propicie uma cópia fiel, correspondente em todos os pontos, ao próprio fenômeno; pelo contrário, sabemos que muitos aspectos da realidade nos escapam, ainda que sob o foco dos instrumentos que desenvolvemos para aproximá-la ou ampliá-la. Na verdade, a realidade ontológica, o Umwelt, pouco ou nada tem a ver com a realidade logica, o Innenwelt; e mesmo o controle que, supostamente, exercemos sobre o mundo nos permite supor uma correspondência entre ele e nossa percepção, pois aquele é detectado por esta e, por conseguinte, Innenwelt também, e não podemos, baseados apenas ar, tentar provar sua eficácia, que tal intenção não resistiria a qualquer análise logica, mesmo a mais elementar. Podemos concluir pois, que a investigação em ciência é uma atividade essencialmente intelectiva, e não empírica, como o querem seus seguidores, e, nesse aspecto, não existe qualquer diferença, qualitativa ao menos, entre ela e a investigação de natureza filosófica: ambas são produtos de atividades puramente mentais e têm um ponto de partida comum, ou seja, partilham o mesmo objeto de estudo, a natureza, visível ou invisível, que nos engloba, ainda que as intençôes básicas e os objetivos propostos não coincidam inteiramente; por exemplo, ambas sempre tiveram uma preocupação fundamental: explicar o "mistério" da existência, o significado do próprio fenômeno vital e, por extensão, suas perspectivas mais remotas, embora o façam, como dissemos, segundo metodologias diferentes.

Mas, por mais que se estude e se aprofunde, dentro dos postulados da ciência oficial, o mistério da existência, a nada chegaremos e coisa alguma compreenderemos, pois ele se esconde por detrás do observável, além do mensurável, para lá do concre to e do palpável. Tampouco filosofia alguma poderá nos dizer dos objetivos e do significado da vida, mesmo que, por vida, entendamos a totalidade do processo evólutivo, pois a lógica filosófica, apesar de nâo se limitar ao concre to e ao viśrvel, é limitada pelo próprio tempo e espaço que definem o filósofo.

Conquanto ambas reconheçam, na existência, um processo dinâmico de transformações, elas têm, a apartá-las, o enfoque básico do problema: enquanto os filósofos crêem, com poucas exceções, num lado de dentro de todas as coisas, em sua estrutura mais íntima, os cientistas se detêm apenas no seu lado de fora, em suas manifestações extrínsecas. Estes, especialmente os biblogos, em sua quase totalidade, se recusam a ver uma orientação e um sentido intrínsecos à mecânica evolutiva, enquanto os filósofos, apesar de reconhecê-los, não conseguiram, pelo menos até hoje, precisá-los. Esboça-se assim, o hiato existente - e que se alarga à medida que novos dados são coligidos e interpretados entre a Ciência e a Filosofia, pois, embora abordados sob metodologias dife- 
rentes, as interpretações dos fenômenos deveriam convergir para resultados, senão idênticos, ao menos complementares, para que pudéssemos classificá-las, uma e outra, como formas consistentes da aproximação da realidade. Há então, essa insuficiência, mutuamente determinada, da Ciência e da Filosofia, em lançar alguma luz à mecânica de todos os fenômenos, redutível, em última análise, a suas deficiências metodológicas, e não podemos, baseados exclusivamente nos resultados ou proposições de uma, tentar provar a falsidade da outra.

Pertencemos a uma comunidade que pretende, através do método científico, explicar os fenômenos que nos cercam. Observamos, por conseguinte, esses fenômenos e a natureza que nos engloba, o mundo que nos rodeia, tentando, equacionar ao menos, a vida e a existência; mas, se é essa nossa intenção básica, não devemos, em nossas observaçoes, nos prender à cultura que, de alguma forma, nos moldou; às experiências, no passado, com algum fenômeno ou evento similar ao fenômeno ou evento presente; e mesmo às nossas sensações imediatamente anteriores ou posteriores ao fenômeno, numa sugestão clara de eventos antecedentes e eventos conseqüentes.

Coisa alguma pode ser analisada à luz (ou à sombra ) de uma cultura que, por dogma e tradição, se detém apenas nas manifestações perceptŕveis de um fenômeno, nas suas ações e interaçôes com uma partícula do cosmo que lhe é adjacente, desprezando ou ignorando todos os seus outros aspectos. Para se tentar compreender um fenômeno, é necessário que nos voltemos para ele, despidos de todo o preconceito, sem desprezar certas manifestaçōes raras que julgamos aperiódicas e sem elaborar hipóteses exclusivas para explicá-las. Nesta última afirmativa está implícita uma noção cíclica: de fato, é possível que o universo seja rítmico e também todos os fenômenos e todos os seres que o compõem, do mais banal ao mais marcante; do invisível, porque ínfimo, ao impressionante, porque enorme; do mais raro ao mais corriqueiro. Não existiriam então, as exceções aberrantes, os eventos aperiódicos, os acontecimentos aleatórios; a Ciência é que, impotente para decifrálos, assim os classificaria para que se ajustassem a suas teorias e sistemas, a suas leis e postulados; na verdade, a Ciência não se adapta aos fatos, mas - absurdo - tenta adaptar os fatos a si, desprezando ou ignorando aqueles que lhe são contraditórios, ou ainda, num supremo exercício de imaginação, inven- tando hipóteses ou explicaçõs ad-hoc para esses fatos. Todos temos, é claro, uma concepção própria e característica do universo, uma estrutura teórica sob a qual ordenamos as informações que coletamos, mas, sem dúvida, devemos ignorá-la no instante da observação, embora ela deva ser testada a partir das experiências daí resul tantes, e até reformulá-la integralmente, quando frente a evidências contundentes do contrário

Nossas experiências passadas também não servem para o entendimento pleno de um fenômeno, qualquer que seja, antes, elas apenas nô-lo prejudicam pois, embora todas as coisas possam estruturar-se e manifestar-se segundo uma mecânica única, são, sem exceção, absolutamente diferentes umas das outras. Além disso, estaríamos correndo o risco de classificar aprioristicamente um dado fenômeno, segundo uma escala de valores estruturada em ocasiões passadas e baseada, em última instância, em nossa integridade biologica. Qualquer fenômeno, antes de suas eventuais similaridades, é único e genuíno; para entendê-lo pois, devemos olhá-lo como tal e não buscar pontes ou elos entre ele e outros fenômenos.

Tampouco devemos observar um fenômeno baseados apenas em seus eventos antecedentes ou conseqüentes, ou nas sensações experimentadas pouco antes ou depois de sua manifestação; estaríamos simplesmente deixando de olhar o fenômeno dentro de seus parâmetros têmporo-espaciais e, esquecidos de seu epicentro, de seu fulcro, buscando compreendê-lo num ćŕrculo mais amplo do tempo e do espaço, onde poderíamos ver apenas suas causas e conseqüências, se tanto, já distorcidas pelo próprio tempo e espaço. Há, aqui, é claro, uma preocupação em prever, probabilisticamente, a ocorrência futura do fenômeno sob investigação e, por conseguinte, controlá-lo, desenvolvendo assim uma tecnologia especifica. Não obstante, não devemos entender a Ciência por Tecnologia, embora uma possa ter sungido da outra e sigam por caminhos paralelos ou mesmo entrelaçados: hoje, esta é gerada por aquela, e, conquanto uma condicione o aperfeiçoamento da outra, é preciso entender a Tecnologia como um mero subproduto a avaliar o progresso e o desenvolvimento da própria Ciência. Mas, é possível que a Tecnologia deixe de ser, em um futuro próximo, a única maneira de avaliar uma área de conhecimento científico. Podemos supor, baseados na Astrofísica por exemplo, que a Ciência deverá ser julgada pelo próprio conhecimento que gerou, inde- pendente do valor pragmático desse conhecimento ou de sua transformação em tecnologia. $O$ homem intenta conhecer o seu derredor também para avaliálo e a sua posição dentro dele, e não apenas para manipulá-lo ou alterá-lo. Esse produto da Ciência deve ser suficiente para manter a sua atividade investigatória, ainda que reste uma possibilidade remota de aplicação daquele conhecimento, senão, como explicar o processo de investigação filosófica? No entanto, alguns dados ou hipóteses da Astrofísica não servem a qualquer propósito, ao menos para os homens que os coligiram ou propuseram, de sorte que, ou aceitamos uma "consciência da espécie" ou o valor do conhecimento em si mesmo. Claro está, que poderfamos explicar essa atividade de investigação ou reflexão em termos de um controle essencialmente social, isto é, de prestígio ou status grangeados dentro de uma comunidade específica, mas tal pode ocorrer tanto em relaçâo ao cientista quanto em relação ao filosofo, e isto apenas corrobora a idéia de uma ciência não geradora, obrigatoriamente, de tecnologia. Existem alguns aspectos que evidenciam a importância e a suficiência do conhecimento em si, independente do uso que faremos dele: há, entre os homens, uma necessidade imanente de compreender as coisas que os cercam, ou aquelas que eles imaginam; de buscar respostas para as perguntas atenazantes que lhes brotam na mente sobre suas origens e as origens de todas as coisas; sobre a gênese do universo e seus limites; enfim, aquilo que satisfaca a curiosidade sobre suas existências até as últimas conseqüências, até o primeiro sopro que os animou, até a espátula que os moldou. Os filosofos, sem exceção, acredito, reconhecem essa necessidade do homem explicitar o fenômeno da existência (o que, talvez, o tenha levado a desenvolver a própria Ciência e a Filosofia e, quando frente a uma realidade mais poderosa - porque mais ampla no tempo e no espaço que seu intelecto - a inventar a Religião).Estes, no entanto, não nos explicam, por inteiro, o fenômeno humano; tampouco os teólogos o fazem, ainda que ousando mais e sustentando que o homem só o é em função do "espírito" que se alojou em cada um e não do tempo atuando sobre seu organismo. Na verdade, o homem não pode ser compreendido isolado de seu universo biológico, apartado de sua árvore evolutiva, separado de seu processo histórico; é nos animais, porque mais próximos do gênero humano que os vegetais ou minerais, que devemos procurar entender o fenômeno 
humano e suas perspectivas. Natura non facit saltus. Essa a verdade proclamada por quase todos; aceita, com raras excecoes, universalmente. Os elementos natutais são classificados, e evoluem, sobre um plano ascendente onde, podemos dizê-lo, inexistem os degraus. Há mesmo uma confusão entre os limites do mundo animado e do mundo inanimado: não se conhece, ao certo, onde começa a vida e termina o mineral. Tampouco se sabe, em suas fronteiras, onde a vida é animal e onde ela é vegetal ( a Euglena por exemplo, e outros flagelados clorofilados, é considerada um animal pelo zob́logos e uma planta pelos botânicos, que a incluem na divisão Euglenophyta). A transição de uma classe de seres a outra, como daí se depreende, não se processa de uma maneira brusca, mas sim através de um gradiente de transformaçōes onde características de um ser ontologicamente mais evoluído vão sendo apresentadas, a pouco e pouco, por seres menos evolurdos. E vemos, dessa maneira, a hominização sendo esboçada e ensaiada ao longo da escala zoológica; constatamos - entre assombrados e indignados - características quase humanas entre os demais animais, especialmente os antropóides.

Há, no entanto, ao menos para nós, uma linha demarcada e nútida a nos apartar dos outros animais; somos pois, como os teólogos, tentados a ver, no fenômeno humano, um significado que vai além da simples continuidade do processo evolutivo, reconhecendo nele, ou tentando, um elemento novo e insólito na história do mundo: o homem não seria apenas o ápice da escala zoológica (e aí está implícito que, talvez, ele não seja a forma derradeira moldada pelo processo evolutivo) mas, uma seta apontada para $o$ alto e para lá se dirigindo; $e$, mesmo reconhecendo a inexistência de qualquer hiato entre nós e outros animais, ainda gostaríamos de sustentar nossa singularidade, vendo, ar, o fenômeno humano sendo preparado, há muito, ao longo da escala ontológica, como um cone, cujas linhas componente se juntam mais e mais à medida que se aproximam do vértice, até o momento em que lá se encontram e, prolongando-se para cima, acabam por se cruzar, de sorte que sua face interna passa a ser externa, e esta passa a ser a face interna. Nesta figura, vista allures, gostaríamos de ver explicado o fenômeno da hominização que, separado irreversivelmente de outras existências, não teriam, a apartá-los, um degrau ou uma defasagem.

Mas, devemos entender o fenômeno humano como um fator de complexi- dade biológica e, é claro, analisá-lo sob uma perspectiva evolutiva. No momento em que o homem, descendo das árvores onde sempre viveu, adotou uma postura bípede, suas mãos passaram a ser utilizadas mais para manipulação e exploração que para apoio. Com isso, sua força mandibular regrediu e, com ela, a expessura de sua caixa craniana, possibilitando, assim, um considerável aumento, estrutural e funcional, de seu cérebro. Este, muito mais desenvolvido, permitiulhe uma observação muito mais refinada e eficiente de seu ambiente, e, também. como vimos, o desenvolvimento de instrumentos e ferramentas para "domesticá-lo"; além disso, o homem desenvolveu uma forma de comunicação altamente sofisticada que the facultou a transmissâo de todo o conhecimento adquirido a seus descendentes. Falamos, indiscriminadamente, de um homem e do fenômeno humano; de um momento especifico e do processo temporal, embo ra tanto um quanto outro não constituam agregados reais, mas sim, abstrações. No entanto, algumas línguas, como o Hopi, não conhecem as abstrações, não falam por metáforas: referemse a uma gota de água, ao rio e ao mar, mas jamais à água em geral; citam um homem em particular mas desconhecem a "condição humana"; falam do agora mas não do tempo. A linguagem pois, também determina uma visão característica do mundo e, por conseguinte, seleciona os aspectos da realidade a serem considerados e proporciona uma maneira específica de interpretá-los.

A transmissão do conhecimento, adquirido por uma geração, à geração seguinte, possibilitou o incremento e o aperfeiçoamento desse conhecimento. 0 conhecimento cumulativo é, por certo, uma das características básicas e exclusivas do gênero humano, a partir da qual foi possível desenvolver a Ciência e a Filosofia ao ponto que as temos hoje; e a aquisição desse conhecimento se alicerça, sem dúvida, sobre uma atividade observacional.

Po rém, as informações passadas, as experiências anteriores, e a preocupacão exclusiva com eventos antecedentes e eventos conseqüentes nos definem e nos limitam como observadores e, mais que tudo, nos apartam do próprio fenômeno observado. Há sim, é claro, uma defasagem entre um e outro, mas, creio, essa deve ser a mais pura possivel, despida de todos os preconceitos e valores e reduzida à dimensão do presente. Isso não significa que não devemos tentar integrar nossas experiências do particular em sistemas mais amplos, descobrir o universal a partir do especifico, compreender o universo todo, partindo da compreensão - ou da observação meticulosa - de algum de seus múltiplos aspectos, mas, que nos posicionemos, sem intençōes ou expectativas, frente ao fenômeno ou evento a ser observado. Resta, sem dúvida, a estrutura do observador e do observado a apartá-lo, e, quando se trata de seres vivos, esta determina uma certa sensibilidade, uma gama de sensações especrficas, uma visão característica do mundo circunstante e, não sei até que ponto, o observad or não passa também à condiçâo de observado.

Não tem sido esta, por certo, a atitude da Ciência. Hoje, ela se converteu e se resumiu, mais que tudo, na própria metodologia que, um dia, se mostrou útil e eficiente para começar a explorar racionalmente o mundo que cercava e englobava o cientista. Este, mais que um observador e um formulador de questôes, transformou-se num crítico metodológico; mais, num censor, condenando e proibindo todos os fatos e todas as abordagens desses fatos que não se adaptem aos "sagrados" cânones da Ciência.

No entanto, creio que a Ciência está por atingir os limites tecnolbgicos de exploração do universo, ou seja, já desenvolveu, ou quase, todos os instrumentos que lhe permitiam ampliar ou aproximar os eventos e fenômenos em estudo para melhor analisá-los e mensurá-los. Por certo, as possibilidades analiticas ainda não se esgotaram de todo; até um novo campo se lhe é aberto com os resultados dos programas espaciais que, embora não aproximando ou ampliando um fenômeno específico, podem trazer ou transmitir esse fenômeno até ao cientista ou levá-lo até às proximidades do próprio fenômeno. Porém, mais que um alento à análise, este fato, creio, deve ampliar as intenções e perspectivas do método científico, transformando-o mesmo. Assim, a análise e a mensuração, e com elas a metodologia científica atual, estão, por assim dizer, em seus estertores. Essa mudanca metodológica já se antevê na Fŕsica, na Qứmica, e mesmo na Biologia, que substituem a experimentação pela especulação, a manipulação de partículas do cosmo por modelos matemáticos mais amplos, deixando de lado a lógica cartesiana $\mathrm{e}$ as representações euclidianas.

Não qeuro, com isso, dizer que esses ensaios de novas metodologias, que esses primeiros passos de uma abordagem inédita dos fenômenos seja a definitiva ou aquela que mais próximo nos le- 
vará da realidade de todas as coisas. Mas, talvez, esta sirva como um elo a nos libertar das coisas materiais, palpáveis, mensuráveis - material, palpável e mensurável para nossos sentidos, ainda que ampliados pelos instrumentos que desenvolvemos - antes de nos possibilitar uma abordagem mais ampla e mais completa dos fenômenos que estudamos. Aŕ entáo, a Ciência há de se voltar, e se deter nos aspectos até então desprezados dos fenômenos que estuda; ela, por certo, passará a considerar, não apenas as manifestações circunstanciais de um fenômeno, mas, também, o próprio fenômeno; o dentro tanto quanto $o$ fora das coisas.

\section{BIBLIOGRAFIA}

CHARDIN, P. T. - O fenômeno humano. São Paulo, Herder, 1966.

DETHIER, V. G. \& STELLAR, E. - Comportamento animal. São Paulo, Edgar Bücher, EDUSP, 1973.

EIBL-EIBESFELDT, I - Ethology: the biology of behavior. 2.ed. New York, Holt, Rinehart and Winston, 1975.

GOTT, J.R. et alii - "Will the universe expand forever?" Sci Am, 234(3):62-79, 1976.

MORRIS, D. - O macaco nu. São Paulo, Edibolso, 1975 .

PILBEAM, D. $-A$ evoluf̧ão do homem Lisboa, Verbo, 1973.

WEATHERALL, M. - Metodo cientifico. São Paulo, Polígono, EDUSP, 1970.

\section{Doenças Sexualmente Transmissiveis}

\section{RESULT ADOS DA APLICAÇÃO DE UM QUESTIONÁRIO DE CONHECIMENTOS BÁSICOS SOBRE DOENÇAS SEXUALMENTE TRANSMISSIVEIS EM COLEGIAIS.}

Trabalho apresentado no I Seminário Latino-Americano sobre Doenças Sexualmente Transmissf́veis, Goiânia, outubro de 1977

Colaboradores
ANA MISAKO Y. ITO
Centro de Ciências da Saúde
PROF. NILTON L. TORNERO
MARItre em Saúde Pública
Centro de Ciências Exatas
HARUMI TAKANO
Centro de Ciências Exatas
VERA LUCLA GUISELLI
Centro de Ciências Exatas

\section{RESUMO}

Como parte de um projeto sobre doenças sexualmente transmissiveis que está sendo desenvolvido no municipio de Londrina, Paraná, os autores apresentam os resultados obtidos através da aplicação de um questionário básico sobre o assunto a colegiais. Partindo-se de uma amostragem por conglomerados, estudou-se várias caracteristicas da população, como idade, sexo, estado civil, episódios de doenças sexualmente transmissiveis, periodo de estudo, etc. Os conhecimentos foram medidos

\section{ABSTRACT}

As a part of a project about diseases sexually transmitable, which is being developed in Londrina, state of Parana, the authors present the results that were obtained through a basic questionnaire about these diseases answered by high short students. Starting from a sample by comglomeration, several characteristics of the population such as age, sex, episodes of diseases sexually transmitable, periods of study, etc. were studied. The knowledge about the diseases were measured through a score and considered low (56,4\% right per questionnaire).

The score was also a nalysed in relation to other circunstances and the conclusion was that the two more important parts factores that interfere in the knowledge are the masculine sex ande age. The conclusion was that the population involved in the research is in danger, which justifies a program of information in the matter. The suggestion is that this information could be done by high school students especiallu trained, who might be better acepted by their own colegues.

UNITERMOS: Doenças Sexualmente Transmissiveis; Conhecimentos de Doenças Sexualmente Transmissíveis por Colegiais.

\section{INTRODUÇÃO}

Os autores estão desenvolvendo um projeto sobre doenças sexualmente transmissiveis (1) (principalmente gonorréia e sífilis) no município de Londrina, visando a estudar o problema em nível local, sob diferentes ângulos, com o objetivo de quantificar algumas variáveis, úteis como subsíd io em um programa de controle.

Por outro lado, todo programa, quer local, quer a nível mais amplo, não pode prescindir da, educação sanitária. Esta atividade deveria acompanhar os indivíduos desde a infância; quando isto se torna impossível, deverá ser dirigida pelo menos aos grupos de alto risco.

Com o propósito de desenvolver um trabalho de educação sanitária nos grupos de alto risco - colegiais, universitários, industriários - preparou-se o presente questionário. Procura-se colher informações básicas sobre o assunto, bem como caracterizar essas populaçôes. Este informe refere- 